\title{
MASTER
}

GA-A16085

\section{TARGETS FOR HIGH POWER NEUTRAL BEAMS}

\author{
by \\ JINCHOON KIM
}

NOVEMBER 1980

\section{GENERAL ATOMIC COMPANY}




\section{DISCLAIMER}

This report was prepared as an account of work sponsored by an agency of the United States Government. Neither the United States Government nor any agency Thereof, nor any of their employees, makes any warranty, express or implied, or assumes any legal liability or responsibility for the accuracy, completeness, or usefulness of any information, apparatus, product, or process disclosed, or represents that its use would not infringe privately owned rights. Reference herein to any specific commercial product, process, or service by trade name, trademark, manufacturer, or otherwise does not necessarily constitute or imply its endorsement, recommendation, or favoring by the United States Government or any agency thereof. The views and opinions of authors expressed herein do not necessarily state or reflect those of the United States Government or any agency thereof. 


\section{DISCLAIMER}

Portions of this document may be illegible in electronic image products. Images are produced from the best available original document. 


\section{DISCLAIMER}

This report was prepared as an account of work sponsored by an agency of the United States Government. Neither the United States Government nor any agency thereof, nor any of their employees, makes any warranty, express or implied, or assumes any legal liability or responsibility for the accuracy, completeness, or usefulness of any information, apparatus, product, or process disclosed, or represents that its use would not infringe privately owned rights. Reference herein to any specific commercial product, process, or service by trade name, trademark, manufacturer, or otherwise, does not necessarily constitute or imply its endorsement, recommendation, or favoring by the United States Government or any agency thereof. The views and opinions of authors expressed herein do not necessarily state or reflect those of the United States Government or any agency thereof. 
GA-A16085

\title{
TARGETS FOR HIGH POWER NEUTRAL BEAMS
}

\author{
by \\ JINCHOON KIM
}

This is a preprint of a paper to be presented at the Conference of the Application of Accelerators in Research and Industry, Denton, Texas, November 3, 4, 5, 1980.

\author{
Work supported by \\ Department of Energy \\ Contract DE-AT03-76ET51011
}

GENERAL ATOMIC PROJECT 3235

NOVEMBER 1980

\section{GENERAL ATOMIC COMPANY}




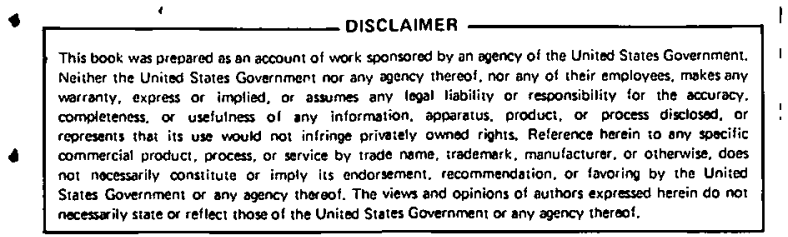

Summary

Stopping high-power, long-pulse beams is fast becoming an engineering challenge, particularly in neutral beam injectors for heating magnetically confined plasmas. A brief review of neutral beam target technology is presented along with heat transfer calculations for some selected target designs.

\section{Introduction}

Since most of the large, next-generation tokamaks and mirror devices will require neutral beam injection (NBI) heating, increasingly higher beam powers will be demanded in order to obta in reactor-grade plasma temperatures. For instance, the Tokamak Fusion Test Reactor (TFTR) is designed for an NBI power of about $2 \mathrm{C}$ iW and an engineering test reactor is slated for more than $50 \mathrm{MN}$. Total (neutrals and ions) peak power densities normal to the beam axis are typically a few tens of kilowatts per square centimeter for present IIBI systems 1 and higher yet for future systems. Stopping such beams is no longer a trivial problem.

A typical beamline 2 consists of an ion source, a closely-coupled neutralizer gas cell, a separation magnet for the residual ions from the neutral particles' passage, an ion beam dump to stop such separated ions, a retractable calorimeter target in a drift duct connecting the beamline to a fusion device, and, in a test facility, a target simulating the location of the fusion plasma. In the injection mode, the beam power is absorbed by the plasma column (for neutrals) and by the ion beam dump (for residual ions). In the beamconditioning mode, the neutrals are stopped by the calorimeter target instead. When beam diagnostics require the total beam (neutrals plus ions) or when the separation magnet is accidentally turned off, however, the drift duct calorimeter target will be irradiated by the total beam. It is therefore desirable to design a target capable of handling the total beam power. Power loading to the ion beam dump relative to the total beam power increases as the beam energy increases because the ion-to-neutral conversion efficiency decreases with increasing energy. The ratio of the neutral fraction to the ion fraction for an equilibrium neutralizer gas cell is given as $f_{0}{ }^{\infty} / f_{+}{ }^{\infty}=\sigma 10 / \sigma_{0 l}$, varying (for instance, for protons) from 1.5 at $40 \mathrm{keV}$ to 0.25 at $100 \mathrm{keV}$.

In general. two types of target design have been used: 3 an actively cooled target and a "thermal inertia" target. Beam pulse length, beam power density, and duty cycle dictate the choice of target. It seems apparent that one could not enjoy a comfortable safety margin in future beam target designs and hence that careful heat transfer calculations are essential. This paper presents a general (although not complete by any means) review of beam target status, a survey of heat transfer calculations for some selected target designs, and a comparison of the calculations with some limited experimental data that is available. It is noted that heat transfer considerations for beam targets are also applicable to other components in a fusion device: ion source components, limiters, armor plates, and divertor targets, for example.

\section{Design Variations of Beam Targets}

Neutral beams are typically of large size and cperated in a pulsed mode; these two properties have significant implications on beam target design. Since the beam targets have to be large, mechanical strength is of concern. Since they are pulsed, it is possible to employ a target of high thermal inertia whose surface temperature is proportional to the square root of the pulse length if the target is sufficiently thick. As the beam pulse length $\left(t_{p}\right)$ is increased, the useability of the thermal inertia target diminishes and an actively cooled target is needed.

Removal of the neutral beam energy deposited on a target depends on conduction across a thickness $(\delta)$ and convection across the solid-fluid interface. The relative merit is described by a parameter called Biot number, $B=h \delta / k$. (If the respective cross sectional areas for the two processes are different, the Biot number should be corrected for the areas.) $h$ and $k$ are respectively the convective heat transfer coefficient and the thermal conductivity of the solid. In general, when $B$ is small (e.g., for an inertia target), say less than -0.2 , the body temperature rapidly becomes uniform and will be cooled down like $1-\exp \left(-t / \tau_{c}\right)$ where $\tau_{c}=$ $\mathrm{\rho C} \delta / \mathrm{h}$ is the convective time constant. When $B$ is large $(\geq 10)$, the time behavior is governed by the thermal diffusion time $\tau_{d}=\delta^{2} / \alpha$, where $\alpha=k / \rho C$ is the thermal diffusivity. The overall thermal time constant can be defined as $\tau_{t h}=\tau_{c}+\tau_{d}=\tau_{c}\left(1+B_{i}\right.$. If the beam pulse length is long (at least a few times $\tau_{t h}$ ), the heat transfer can be treated as steady state.

\subsection{Actively Cooled Targets}

Actively cooled targets are suitable for steadystate or high-duty-cycle operation in which the heat input rate and the convective heat transfer rate must be balanced. The simplest design would be a thin flat plate with one side intercepting beams and the other side cooled by means of a coolant channel. There are a variety of design variations from this simple model that can improve the value of heat transfer coefficient and/or increase the irradiation area for reduction of input power density. Some examples are discussed bełow. The coolant channel of the thin target mentioned above can be divided into a number of small channels (for example, by an etching technique) to allow a higher coolant pressure and added mechanical strength. A rotating target design, which can increase the irradiation area, has also been in use for various beam targat applications, including the Rotating Target Neutron Source 4 at Lawrence Livermore Laboratory, in $\therefore$-ray tubes, 5 and recently for a neutral beam target. 6 The size of the target must be much larger than the size of the beam so it will have a large "sweeping" area. A high rotation also yields a large timeaveraged irradiation area ( $\leqslant$ a few thousand $\mathrm{rpm}$ ). The latter design for the TEXTOR neutral beaml ine6 employs two rotating drums, each intercepting half of a largesize beam.

One other way of increasing both the irradiation area and the cooling rate is to assemble a target from a number of tubes. A tube has several advantages as a target element over a flat plate: (i) it has an irradiable area $\pi / 2$ times larger, and the heat input density decreases with $\cos \phi$ for a parallel beam (see Fig. 1); ( $i i)$ two-dimenstonal cooling (in $r$ and $\phi$ ) is more effective when only a portion of the tube circumference is trradiated; and $(i i j)$ it has more mechanical rigidity and greater flexibility in arrangement. However, a crucial disadvantage is that the heat flux density on the inner surface can be as high as $r_{0} / r_{i}$ times the input heat flux density at the outer surface. 


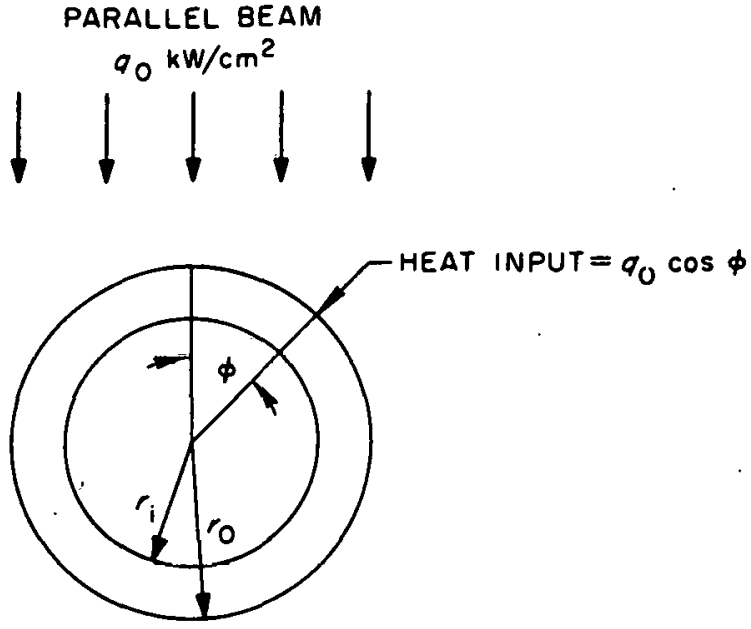

Figure 1. A single tube exposed to a parallel heam.

As shown in Fig. 2, two basic arrangement schemes are possible, with a third one derived from a combination of the first two. In a type (a) arrangement, the tube axis can be inclined to a small angle $(\alpha)$ to the beam direction to reduce the input power density by $\sin \alpha$. The type (b) arrangement has only one layer of tube arrays, running in a direction normal to the beam axis, each tube on top of another providing a "shadow" and thus reducing the peak power density by $\cos \phi_{0}$. If a type (b) target is tilted with respect to the beam direction about the centerline of the target plane normal to the tube axes, it becomes type (c) and the power density can be reduced by $\sin \alpha \cos \phi_{0}$ in the type (a) arrangement, the tube length tends to be very long $\left(\sim D_{\text {beam }} / \sin \alpha\right)$ by comparison with type (b) tubes $(\sim$ Deam $)$, and higher pumping powers are required. In type (b), however, reduction of the peak power density by shadowing is not significant unless the degree of shadowing, $\phi_{0}$, is fairly large $\left(<90^{\circ}\right)$, in which case the number of tubes becomes considerably larger, requiring a large total flow rate.

The heat transfer characteristics of such tube targets can be further enhanced by the generation of additional turbulence. A spirally twisted tape can be swaged inside a tube to generate a swirl flow. 7 The inner wall of a tube can be finned straight or helical, to improve the heat transfer. 8 Targets made of swirl tubes have been used successfully in neutral beam injectors ${ }^{9}$ (see below). A hybrid of swirl tubes and finned tubes has also been considered, with a coaxial rod inserted tightly inside a helically finned tube to use the total flow rate economically without losing the merits of the swirl flow. 10

\subsection{Thermal Inertia Targets}

Owing to simplicity in design, fobrication, and heat transfer mechanism, the thermal inertia target has been used extensively in neutral injector systems 11 whose beam pulse length is relatively short. Beam energy is absorbed by the mass of a target during a beam pulse and slowly transferred to cooling water channels on the back side during the longer off cycle. The main design criteria are the thermal and mechanical properties of the target material rather than the convective heat transfer properties of the coolant.

Typical neutral beam targets are made of thick copper plates with minimal cooling on the back. Two plates are formed in a $V$-shape to reduce the average power density as well as to minimize the axial length taken up by the target. Such a thick-plate target also permits good access to diagnostics such as thermo-

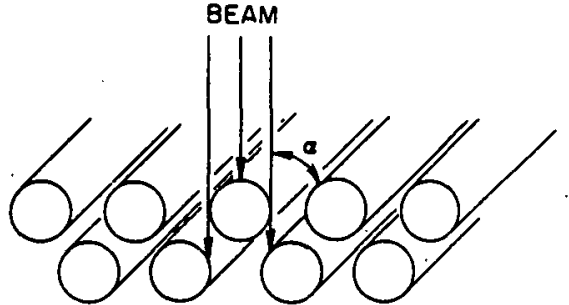

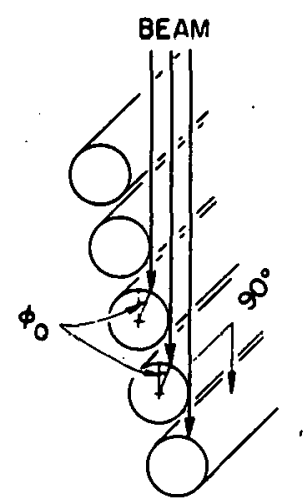

(b)

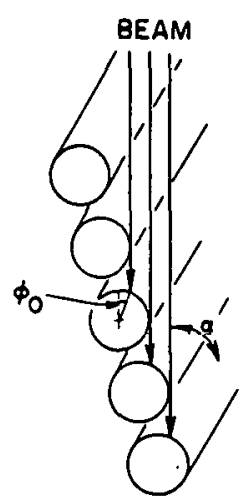

(c)
Figure 2. Variations of tube arrangements to form a target.

couple arrays. Owing to the high surface temperatures inherent in this type of target, however, thermal stress is one of the primary concerns. In order to relieve the thermal stress, for instance, designers of the JT-60 (the large Japanese tokamak) injectors have employed about 800 independent squares $(3 \times 3 \mathrm{~cm})$ to form a large surface. 12

The ablation target made of high temperature refractory materials relies on thermal radiation and evaporation as cooling mechanisms. A tantalum-carbide disk has been tested as a possible beam target.13 A mean power density of $20 \mathrm{~kW} / \mathrm{cm}^{2}$ with a pulse length of $0.1 \mathrm{~s}$ was handled on a disk $12 \mathrm{~cm}$ in diameter with radiation cooling only. Carbon was observed to evaporate preferentially. The pyrolitic properties of certain. graphite crystals can also be used in a design that can benefit the directional enhancement of thermal conduction.

\section{Swirl Tube Heat Transfer}

It has been shown experimentally that the ratio of swirl flow to axial flow burn-out flux is about 2 under the same pumping power and that the swirl flow is most beneficial with either bulk boiling or subcooled local boiling. 7 Reported experimental studies are mostly for the case of steady-state, uniform heat input. In beam target applications; however, the input heat flux is highly nonuniform in both the azimuthal and the axial directions. Here we briefly review. swirl tube heat transfer studies available in the literature, for the steady-state uniform heat input case. Nonuniform heat input cases are then discussed along with some experimental observations in neutral beam target applications.

\subsection{Uniform Heat Input Case}

Nonbolling Heat Transfer. Heat transfer of a swirl tube is enhanced due to (i) additional turbulent flow generated in the spiral channel, (ii) the centrifugal convection effect, and (iii) the tape acting as a fin. The fluid velocity increase over the axial flow can be described by a rotating slug flow model, 7 which yields the fluid velocity at the inner wall in terms of the tape twist ratio ( $y=$ axial length of $180^{\circ}$ twist 
divided by the inner diameter) and the axial flow velocity $\left(V_{a}\right)$,

$$
v_{s}=v_{a}\left(1+\frac{a^{2}}{4 y^{2}}\right)^{1 / 2}
$$

While experimental data 74,15 produced various forms $0 ;$ correlations, Lopina and Bergles ${ }^{6}$ derived an expression for the swirl fluw heat transfer coefficient $\left(h_{s}\right)$ accounting for the above three effects in additive mode which agrees fairly well with varied experimental data. A further approximated expression given helow is recommended for use for single-phase flow cases:

$$
h_{s}=\frac{k}{D_{e}} 0.023 F\left(\frac{V_{s}}{V_{a}} \operatorname{Re}\right)^{0.8} \operatorname{Pr}^{0.4}
$$

where $k$ is the thermal conductivity of water, $F$ is a parameter (1.137 for $\operatorname{Re}<3 \times 10^{4}$ and 1.10 for $\operatorname{Re}>$ $\left.3 \times 10^{4}\right), \operatorname{Re}$ is the Reynolds number, $\mathrm{Pr}$ is the Prandt number, and $D_{e}$ is based on equivalent hydraulic diameter.

Pressure drop in a swirl tube can be estimated from friction factor ( $f$ ) correlations through the usual relation for a conduit, the so-called Fanning factor, $f=\Delta p D_{j} /\left(2 L \rho V^{2}\right)$, with the pressure drop $(\Delta p)$ across a length $(L)$ in a fluid having an average velocity, $V$, and the density, $\rho$. According to Lopina and Bergles, 16 the adiabatic (subscript "ad") friction factor of a swirl tube based on the equivalent hydraulic diameter $\left(f_{s}\right)$ is correlated to that for the axial flow $\left(f_{a}\right)$ as

$$
\left(\frac{f_{s}}{f_{a}}\right)_{a d}=2.75 y^{-0.406}
$$

where $\left(f_{a}\right)_{a d}=0.046 R^{-0.2}$, the Colburn relation. The heated friction factor for swirl flow is derived from the adiabatic friction factor in the same manner as for axial flow,

$$
f_{s}=\left(f_{s}\right)_{a d}\left(\frac{\mu_{w}}{\mu_{b}}\right)^{0.35\left(D_{e} / D_{i}\right)}
$$

where $\mu_{w}$ and $\mu_{b}$ are the kinematic viscosities at the inner wall and of the bulk fluid, respectively.

Local Boiling and Burnout Flux. A useful correlation for the case of local boiling is between the liquid film superheat, $\Delta \mathrm{T}_{\text {sat }}\left(\right.$ in ${ }^{\circ} \mathrm{C}$ ) and the wall heat flux, q (in $\left.\mathrm{kW} / \mathrm{cm}^{2}\right)$,

$$
\Delta T_{\text {sat }}=7.76 y^{0.81} q^{1.35}
$$

Gambill, et al. 7 obtained also a few burnout heat flux correlations based on about 40 burnout data, and recommended the following relation for use in target design as a minimum limit,

$q_{b o}=0.079\left(\rho V_{s}\right)^{0.645} D_{i}^{0.24} L_{h}^{-0.44}$

where. $\rho\left(\mathrm{g} / \mathrm{cm}^{3}\right)$ is the density of the bulk fluid, $L_{h}(\mathrm{~cm})$ is the heated length, $D_{i}(\mathrm{~cm})$ is the inner diameter, $V_{s}(\mathrm{~cm} / \mathrm{s})$ is given by $\mathrm{Eq}$. (1), and $q b_{0}\left(\mathrm{~kW} / \mathrm{cm}^{2}\right)$ is the burrout heat flux. They noted that swtrl flow burnout was rather insensitive to the degree of subcooling and the pressure level at the burnout site and that actual physical burnout always occurred at the downstream end.

\subsection{Nonuniform Heat Input Cases}

Twa-Dimensional Heat Conduction. As we have noted earlier, the input heat flux is highly nonuniform azimuthally when a circular tube is placed across a parallel beam. Consequently, the inner-wall flux is nonuniform, making convective heat transfer a very complicated problem. In order to see the effect of azimuthal heat conduction, the two-dimensional steady-state heat conduction equation is solved by assuming that the heat transfer coefficient is independent of inner wall flux variation.

$\frac{1}{r} \frac{\partial}{\partial r}\left(r \frac{\partial T}{\partial r}\right)+\frac{1}{r^{2}} \frac{\partial^{2} T}{\partial p^{2}}=0$,

where $T(r, \phi)$ is the temperature above the bulk coolant temperature. The solution is expressed in terms of Fourier series whose coefficients are determined from the following boundary conditions:

(1) $k \frac{\partial T\left(r_{0}, \phi\right)}{\partial r}=q_{0} \cos \phi$ for $\phi_{0} \leq \phi \leq \pi / 2$

(2) $k \frac{\partial T\left(r_{i}, \phi\right)}{\partial r}=n T\left(r_{i}, \phi\right)$ for any $\phi$

$\frac{I(r, \phi)}{q_{0}}=\alpha_{0}+\beta_{0}$ in $r+\sum_{n=1}^{\infty}\left(\alpha_{n} r^{n}+\beta_{n} r^{-n}\right) \times$

$\left(\cos n \phi+B_{n} \sin n \phi\right)$

where

$\alpha_{0}=\left(k / h r_{i}-\ln r_{i}\right) \dot{B}_{0}$

$B_{0}=\frac{r_{0}}{2 \pi k}\left(1-\sin \phi_{0}\right)$

$\alpha_{1}=\frac{\left(\pi-2 \phi_{0}-\sin 2 \phi_{0}\right)}{4 i k} \cdot \frac{\left(k+h r_{i}\right) \varepsilon}{k(\varepsilon-1)+h r_{i}(\varepsilon+1)}$

$B_{1}=\frac{\left(\pi-2 \phi_{0}-\sin 2 \phi_{0}\right)}{4 \pi k} \cdot \frac{\left(k+h r_{i}\right) \varepsilon}{k(\varepsilon-1)+h r_{i}(\varepsilon+1)}$

$B_{1}=\left(1+\cos 2 \phi_{0}\right) /\left(\pi-2 \phi_{0}-\sin 2 \phi_{0}\right)$

$\alpha_{n}=-\frac{f\left(n, \neq_{0}\right)}{n k} \cdot \frac{\left(n k+h r_{i}\right) \cdot \varepsilon^{n} r_{0}^{-n+1}}{n k\left(\varepsilon^{n}-1\right)+h r_{i}\left(\varepsilon^{n+1)}\right.}$

$\beta_{n}=-\frac{f\left(n, \phi_{0}\right)}{n k} \cdot \frac{\left(n k-h r_{j}\right) r_{0}{ }^{n+1}}{n k\left(\varepsilon^{n}-1\right)+h r_{i}\left(\varepsilon^{n}+1\right)}$

$B_{n}=g\left(n, \phi_{0}\right) / f\left(n, \phi_{0}\right)$

$g\left(n, \phi_{0}\right)=\left(\sin \frac{n \pi}{2}-n \cos n \phi_{0} \cdot \cos \phi_{0}-\operatorname{sinn} \phi_{0} \cdot \sin \phi_{0}\right) / \pi\left(n^{2}-1\right)$

$f\left(n, \phi_{0}\right)=\left(\cos \frac{n \pi}{2}+n \operatorname{sinn} \phi_{0} \cdot \cos \phi_{0}-\cos n \phi_{0} \cdot \sin \phi_{0}\right) / \pi\left(n^{2}-1\right)$

$\varepsilon=\left(r_{0} / r_{i}\right)^{2}$

In Fig. 3, the inner-wall heat flux is calculated as a function of the azimuthal angle for two values of the heat transfer coefficient. In this case, a copper tube $(k=3.5 \mathrm{~W} / \mathrm{cm} \mathrm{K}$ ) is exposed to a parallel beam with a normal density of $q_{0}=1 \mathrm{~kW} / \mathrm{cm}^{2}$, without any shadowing (i.e., $\phi_{0}=-\pi / 2$ ). The input heat flux distribution is 


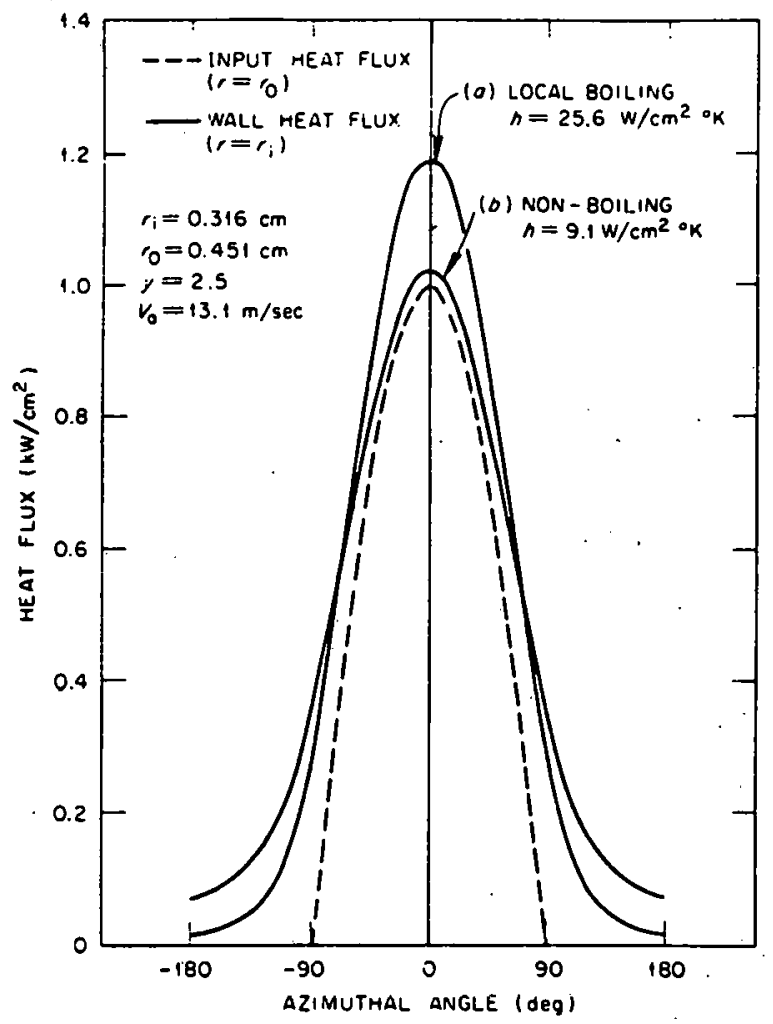

Figure 3. Inner wall heat flux variation as a function of azimuthal angle for the given heat input (dotted line) at the outer wall.

shown by the dotted line. Without the two-dimensional conduction relief the inner wall flux would have been about 1.43 times that of the outer-wall flux. Azimuthal conduction effect depends upon the value of $h$, the cases in Fig. 3 being (a) $h r_{j}>k$ and (b) $h r_{j}<k$. Figure 4 shows what happens when only a quadrant of a tube is expused to the same beam by a shadow arrangemient ( $\phi_{0}$ $=1)$. The peak values of the inner wall flux occur at locations off $\phi=0$. The analysis shown above can be conveniently used in designing tube targets in terms of the optimum tube wall thickness and the shadow arrangement. In reality, however, the heat transfer coefficient varies, likely to be higher on the front side where the heat flux is higher.

Effect of Nonuniform Wall Flux in Swirl Flow. Nonuniformity of the inner-wall flux has an important implication in swirl flow tubes because the cooldnt swirls around alternately the "hot". (front) and the "cold" (back) side of the tube wall. This effect is particularly beneficial in the local boiling regime. One can easily visualize some degree of condensation of the coolant vapor on the back side before the two phase flow hits the front side. The effect apparently will suppress the runaway condition (i.e., burnout) which otherwise would occur. Even in the case of axial flow, an experiment 17 has showed an enhancement in the burnout heat flux of about 1.6 for a nonuniformity of $q_{\max } / q_{\min } \approx 3.8$. In beam target applications, the nonuniformity is very large, e.g., 60 to 100 , and large enhancement is expected for the beam targets. Unfortunately, however, there is very little study made on this type of heat transfer phenomenon.

An example of swirl tube beam tarjet $\left(D_{0}-0.9 \mathrm{~cm}\right.$, $\left.D_{i} \sim 0.63 \mathrm{~cm}, \mathrm{Lh}_{\mathrm{g}}-20 \mathrm{~cm}, V_{a}-15 \mathrm{~m} / \mathrm{s}, y=2.2\right)$ was previously noted in connection with this effect. According to the burnuut flux currelatiun, E4. (7), for the uniform heat input case, the swirl tube would have been melted at about $2.4 \mathrm{~kW} / \mathrm{cm}^{2}$, whereas a normal peak

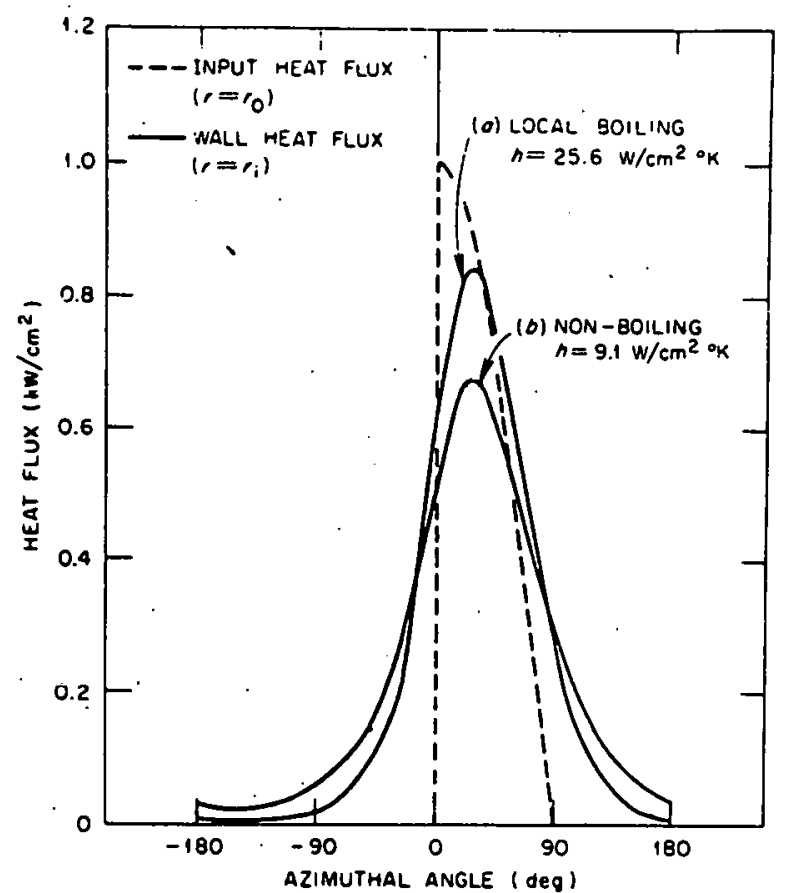

Figure 4. Inner wall heat flux variation as a function of azimuthal angle for the given heat input (cotted line) at the outer wall.

power density of about $6 \mathrm{~kW} / \mathrm{cm}^{2}$ was routinely handled by this target (beam pulse length $-0.3 \mathrm{~s}$ ).

\section{Thick-Plate Inertia Target Heat Transfer}

The present-day neutral beam injectors mostly employ thick-plate inertial targets in which the condition, $\tau_{d} \gg t_{p}$, is readily satisfied. The geometry therefore can be approximated as a semi-infinite slab with no lateral thermal conduction. Inder these conditions, the problem is simplified to a one-dimensional heat conduction with a pulse of heat as the boundary condition:

$\frac{\partial T}{\partial t}=\alpha \frac{\partial^{2} T}{\partial x^{2}} ; \frac{\partial T(0, t)}{\partial x}= \begin{cases}-q / k & \text { for } 0 \leq t \leq t_{p} \\ 0 & \text { for } t>t_{p}\end{cases}$

The complete solutions are:

$T=2 q\left(\frac{t}{\pi k f C}\right)^{1 / 2} e^{-T d / 4 t}-\frac{q x}{k}\left[1-\operatorname{erf}\left(\sqrt{\tau_{d} / 4 t}\right)\right]$ for $t \leq t_{p}$

and

$$
\begin{aligned}
& T=\frac{2 q}{\sqrt{\pi k N C}}\left[\sqrt{t} e^{-T d / 4 t}: \sqrt{t-t_{p}} e^{-\tau_{d} / 4\left(t-t_{p}\right)}\right] \\
& +\frac{g x}{k}\left[\operatorname{erf}\left(\sqrt{\tau_{d} / 4 t}\right)-\operatorname{erf}\left(\sqrt{\tau_{d} / 4\left(t-t_{p}\right.}\right)\right] \text { for } t>t_{p}
\end{aligned}
$$

The surface temperature (at $x=0$ ) monotonically increases with time as $T(0, t)=2 q \sqrt{t / \pi k \rho C}$, peaking at $t=t_{p}$. At a depth, $x=x_{0}$, the maximum temperature occurs at a time that satissfes the following relation,

$$
\ln \left(\frac{n-1}{n}\right)=\frac{-T d / t p}{2 n(n-1)}
$$

where $n=t / t_{p}$ and $\tau_{d}=x_{0}{ }^{2} / \alpha$. 
If temperature behavior after a time much longer than the diffusion time is of interest, for example for analyzing thermocouple array data, the problem should be handied three dimensionally 18 because the thickness of an actual target is finite and the beam intensity profile is not uniform.

In most cases, the one-dimensional analysis suffices. As an example, we will briefly discuss the target used in ISX-B to measure the beam power and profile inside the device. 19 The target was made of stainless steel of $29 \mathrm{~cm}$ by $38 \mathrm{~cm}$ and $0.63-\mathrm{cm}$ thick wit'i cross arrays of thermocouples embedded half-way. Cooling water channels were running up and down through $1 / 4$. inch-tubings $2.5 \mathrm{~cm}$ apart taking up about $20^{\circ}$ of tree backside area. The coolant characteristics yielded $h=1.8 \mathrm{~W} / \mathrm{cm}^{2} \mathrm{~K}$. The diffusion time across the thickness is about $2.3 \mathrm{~s}$ whereas $t_{p}=0.1-0.2 \mathrm{~s}$. A set of measured data was: the total power $=500 \mathrm{~kW}, q=1.5$ $\mathrm{kW} / \mathrm{cm}^{2}$ id center, $t_{p}=0.2 \mathrm{~s}, \Delta \mathrm{J}_{\mathrm{T} / \mathrm{C}}^{\max }=107^{\circ} \mathrm{C}$ center, and the complete cool-down time $=100 \mathrm{~s}$. According to Eqs. (9). $(10)$, and $(11), \Delta T(x=0) \simeq 766{ }^{\circ} \mathrm{C}$ at $t=0.2 . \mathrm{s}$ at center, $\Delta r_{\max }(x=0.32 \mathrm{~cm})=100^{\circ} \mathrm{C}$ at $t=1.26 \mathrm{~s}$, and ith $=26 \mathrm{~s}$. Al though the surface temperature measurement was not available, the peak temperatures at the location of the thermocouple agree quite well betrieen the measurement and the calculation. It is also seen that complete cool-down takes at least $4{ }^{\top} \mathrm{th}^{\circ}$

\section{Conclusions}

Thermal inertia targets have thus far enjoyed a great deal of applications as beam targets where bcam pulse lengths are typically less than one half second. If we allow the surface temperature to rise close to the melting temperature, say $80 \%$, power censities of 3 to $7 \mathrm{~kW} / \mathrm{cm}^{2}$ (varying with target materials) can be handled for one-half-second pulses. Beam pulse lengths longer than 1 second, typical of the next generation neutral injectors, will likely require actively cooled targets. The swirl tuhe and its variations are one of the prospective candidates as a steady-state target, especially in light of burnout flux enhancement due to the inherent flux nonuniformity. While more exotic convertive heat transfer designs are called for, it would be enlightening to point out the theoretical maximum heat flux, which corresponds to the case of $h=\cdot 0$. For a tube, for example, the maximum flux is given as $2 \mathrm{k} \Delta T /\left(D_{0} \ln D_{0} / D_{i}\right)$, yielding $a_{\max } \approx 24 \mathrm{~kW} / \mathrm{cm}^{2}$ for a copper tube of $D_{0}=0.95 \mathrm{~cm}$ and $D_{j}=0.70 \mathrm{~cm}$, where $\Delta T$ is the difference between the melting temperature and the bulk fluid temperature.

Several other areas al so require further work: Thermal stress and sputtering will also be of concern for the cases where the target lifetime is an important factor, such as for fusion power reactors. Direct energy recovery schemes 20 of charged particles, if developed, will ease the ion beam target requirements, which otherwise become nore severe as the particle energy increases.

\section{Acknowl edgement}

Valuable discussions with $D$. W. Doll and W. R. Gambill are gratefully acknowledged. This work was supported by U.S. Department of Energy Contract DE-AT03-76ET51011.

\section{References}

1. J. Kim and J. H. Whealton, Nucl. Instrum and Hethods 141, 187 (1977).

2. See, for exansple, J. Kim, et al., IEEE.Trans. Nucl. Science NS 26, 1281 (1979).

3. J. Kim, R. C. Davis, H. H. Haselton, and C. C. Queen, Proc. of Sixth Symp. on Eng. Problems of Fusion Research (San Diego, 1975), p 194.

4. R. Booth and H. H. Barschal, Nucl. Instrum. \& Methods 99, 1 (1972).

5. Cited in P. Cloth, et al., Proc. Int. Conf. on Radiation Test Facilities for CTR Surface and Materials Program (argonne, 1975) ANL/CTR-75-4, p 243.

6. P. H. Kupschus and C. Meixner (Inst. für Plasmaphysik der Kernforschungsanlage, Julich, Germany). Private comunirication (1979).

7. W. R. Gambill, R. D. Bundy and R. W. Wansbrough, Chem. Eng. Prog. Symp. Series 57, 127 (1961).

8. For example, see R. R. Schmidt and E. M. Sparrow, J. Heat Transfer 100, 403 (1978).

9. J. Kim, R. C. Davis, W. R. Gambill and H. H Haselton, Proc. Seventh Symp. Eng. Protlems of Fusion Research (Knoxville, 1977) Vol II, p 1593.

10. R. R. Feezell and J. Kim (ORNL), unpublished.

11. Use of thermal inertia targets is ubiquitous in injector systems for many tokamaks including ISX-B, PDX, Doublet-III, TFTR, etc.

12. H. Kurijama, et al., Japan Atomic En. Res. Inst. Report, JAERI-1!-8988 (Aug, 1980).

13. W. R. Gambill, et al., Bull. APS 21, 1030 (1976).

14. H. P. Poppendiek and W. R. Gambill, Proc. Third Int. Conf. on Peaceful Uses of Atomic Energy, United Nations, N.Y. Vol 8, p 274-282 (1965).

15. R. S. Thorsen and F. Landis, J. Heat Transfer $90(C)$. 87 (1968).

16. R. F. Lopina and A. E. Bergles, J. Heat Transfer 91, 434 (1969).

17. A. P. Ornatskij and L. S. Vinyarskii, High Temp. $3(3), 400(1965)$

18. J. H. Kamperschroer and J. F. Pipkins, Proc. Eighth Symp. Eng. Problems of Fusion Research (San Francisco, 1979), p 835.

19. S. C. Bates, et al., Oak Ridge National Lab. Report ORIIL-TM-7452 (1980).

20. W. L. Stirling, J. Kim and N. K. Dagenhart, Paper in this Conference. 
N. A. Davies

F. Coffman

One each at following address:

Office of Fusion Energy

Department of Energy

Mail Stop G-234

Washington, D. C. 20545

J. Sheffield

H. H. Haselton

On each at following address:

Oak Ridge National Laboratory P.0. Box Y

Oak Ridge, TN 37830

H. P. Furth

H. P. Eubank

One each at following address:

Princeton Plasma Physics Laboratory

Princeton University

P.0. Box 451

Princeton, N.J 08540

V. L. Komarov

Efremor Institute

Leningrad, USSR

R. V. Pyle

K. H. Berkner

One each at following address:

LBL

University of California

Berkeley, CA 94720

T, Sluyters

Brookhaven Nationa1. Laboratory

Upton, Long Island

New York 11973
E. Thompson

T. S. Green

One each at following address:

Culham Laboratory

Abingdon, Oxfordshire

United Kingdom

E. Speth

Max Planck Institut für Plasmaphysik, Garching bei München,

West Germany

N. N. Semasko

Kurchatov Atomic Energy Institute

Moscow, USSR

S. Matsuda

Japan Atomic Energy Research Institute

Tokai, Ibaraki-ken

Japan

R. R. Stone

Lawrence Livermore National Laboratory

P.0. Box 808

Livermore, CA 94550

M. A. Hoffman

University of California

Baiuer Hal1

Davis, CA 95616

F. Valcx

Centre d'Etudes Nucleaitres

B.P. No. 6

Fontenay-aux-Roses

France

Kyoshi Yoshikaw

Institute of Atomic Energy

Kyoto University

Uzi, Kyoto 611

Japan

Institute of Plasma Physics

Nagoya University

Nagoya, Japan 


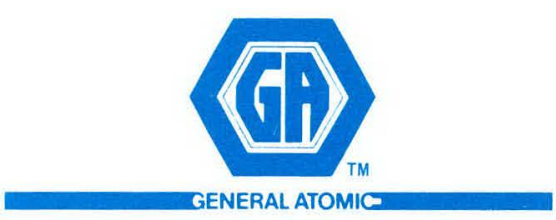

GENERAL ATOMIC COMPANY P. O. BOX 81608

SAN DIEGO, CALIFORNIA 92138 